\title{
Allelopathic Effect of Leaves of Invasive tree Broussonetia papyrifera against some crop plants
}

Anjana Negi ${ }^{*}$, Daizy R. Batish ${ }^{1}$, Harminder Pal Singh ${ }^{2}$ and R. K. Kohli ${ }^{3}$

${ }^{1}$ Department of Botany, ${ }^{2}$ Department of Environment Studies, Panjab University, Chandigarh, India.

${ }^{3}$ Vice-Chancellor, Central University Punjab, Bathinda, India.

Received: December 22, 2015; Revised: January 12, 2016; Accepted: January 21, 2016.

\begin{abstract}
Allelopathic effect of aqueous extracts of leaves of Broussonetia papyrifera (L.) Vent. was studied on germination and seedling growth of Triticum aestivum $\mathrm{L}$. and Oryza sativa $\mathrm{L}$. under laboratory conditions. The seed germination, seedling length, seedling dry weight and total chlorophyll content were reduced with the increasing treatment of concentration $(0.5,1,2$ and $4 \%$ ) of $B$. papyrifera leaf extract as compared to the control. The inhibitory effect was more pronounced on the root length than on coleoptile length. The extracts were rich in phenolic compounds, which are the ubiquitous allelochemicals and often implicated in allelopathy. The study concludes that B. papyrifera exhibits allelopathy through the release of phenolics from its leaves.
\end{abstract}

Key words: allelochemicals; aqueous extract; phenolics.

\section{Introduction}

Allelopathy refers to the beneficial or adverse effect of one plant on another plant through the release of allelochemicals in the environment (Rice, 1984). Allelopathic chemicals can be present in any part of the plant including leaves, stems, roots, flowers or fruits. Various secondary metabolites produced by plants have been considered as potential allelochemicals that plays an important role in shaping interactions and communities. An allelochemical have detrimental effect on the growth of associated crops in agroecosystems (Kohli et al., 1997). A successful establishment of a plant in any ecosystem is attributed to several reasons, such as high growth rate, high reproductive potential, adaptive nature and above all interference by resource depletion and allelopathy (Kohli and Rani, 1994). The plants vary in the amount of secondary metabolites and would release different amounts of the phytotoxins. Generally, leaves are the most potent source of allelochemicals; however, the toxic metabolites are also distributed in all other plant parts in various concentrations. Rainfall causes the leaching of allelopathic substances from leaves which fall to the ground during period of stress, leading to inhibition of growth and germination of crop plants (Mann, 1987).

Broussonetia papyrifera (L.) Vent. (paper mulberry; Moraceae), a native to Asia especially China and Japan, is a deciduous tree usually growing 10 to 20 $\mathrm{m}$ tall. The ability of the tree to form its own monoculture, particularly in disturbed areas, has helped it to become an invasive species in many regions of the world. It spreads rapidly through its roots which produce suckers that form new plants. B. papyrifera is considered to be one of the worst weeds in Pakistan (Malik and Hussain, 2007), in Argentina and in the forests of Uganda (Morghan and Overholt, 2004). In India, B. papyrifera is spreading very fast in North-Western Himalayas

\section{Corresponding Author}

Anjana Negi,

Research Scholar,

Department of Botany,

Panjab University, Chandigarh, India. especially in states of Himachal Pradesh and Punjab. It suppresses the growth of understorey plant species, but the exact reason for the suppression is not clear. One of the reason could be its allelopathic effect on the other plants. However, nothing is known about it. Therefore, a study was conducted to explore the allelopathic potential of $B$. papyrifera leaves on the growth of two crop species i.e. Triticum aestivum L. and Oryza sativa L.

\section{Materials and Methods}

\section{Collection of plant material}

Leaves of $B$. papyrifera tree were collected from Panjab University Campus and surrounding areas. The leaves were shade dried. The plant material (leaves) was ground to a fine powder and stored in polythene bags separately till further use.

\section{Procurement of crop seeds}

The healthy, viable seeds of winter season crop Triticum aestivum L. var. PBW-343 and summer season crop Oryza sativa L. var No. 3 were purchased locally from the seed store.

\section{Preparation of aqueous extracts from leaves of B. papyrifera}

Four $\mathrm{g}$ of dried leaf powder was soaked in $100 \mathrm{ml}$ of distilled water for $16 \mathrm{~h}$ at room temperature $\left(25 \pm 1^{\circ} \mathrm{C}\right)$. The contents were filtered through triple layered muslin cloth followed by Whatman No. 1 filter paper. This $4 \%$ stock solution was diluted further to obtain lower concentrations $(0.5,1$ and $2 \%$ ). These extracts were stored at $5{ }^{\circ} \mathrm{C}$ until used.

\section{Dose response assay}

In laboratory bioassay, the effect of extracts prepared from leaves of $B$. papyrifera was studied on germination and early growth of $T$. aestivum and $O$. sativa. For this, seeds of test crops were soaked in different concentrations of extract solutions (0.5. 1 , 
2 and 4\%) for $24 \mathrm{~h}$ at room temperature. Fifteen seeds of both the test crops were equidistantly placed in $15 \mathrm{~cm}$ Petri dishes lined with absorbent cotton overlined with Whatman No. 1 filter circles soaked with 8 to $10 \mathrm{ml}$ of extract solution. A parallel setup with distilled water served as control. All the treatments were replicated thrice in a completely randomized design. After seven days, percent germination, root and coleoptile length and seedling dry weight of the plants were determined. The seedling dry weight was measured after oven drying the seedling at $80^{\circ} \mathrm{C}$ for $24 \mathrm{~h}$.

\section{Biochemical Estimations}

Total chlorophyll content: The total chlorophyll content was extracted from the leaves of the test plants in dimethyl sulfoxide (DMSO) as per Hiscox and Israelstam (1979), and its concentration was determined spectrophotometrically using the equation of Arnon (1949). The chlorophyll content was expressed in terms of dry weight of the tissue as suggested by Rani and Kohli (1991).

Total phenolic content: The amount of total water-soluble phenolics was determined in leaf aqueous extract using Folin-ciocalteu reagent as per the method of Swain and Hillis (1959).

\section{Statistical analysis}

The data were analyzed by one-way analysis of variance at $p \leq 0.05$ applying post-hoc Tukey's test. The statistical analysis was performed using SPSS/PC software ver. 16.0 (SPSS Inc., Chicago, IL).

\section{Results and Discussion}

It is clear from the study that the B. papyrifera leaf extracts exert a significant inhibitory effect on the germination and growth of T. aestivum and O. sativa. Reduction in the seedling growth (measured in terms of root length and coleoptile length) was observed when test species were grown in Petri dishes with different concentration of $B$. papyrifera leaf extracts. As compared to control, the aqueous leaf extracts of $B$. papyrifera cause inhibition in germination of both the test crops i.e. T. aestivum and $O$. sativa. At $4 \%$ concentration, germination of T. aestivum and $O$. sativa were found to be reduced by approximately $78 \%$ as compared to control (Fig. 1A). The germination percentage decreased with increasing concentration of the extract. Leaf extracts have been regarded as the most phytotoxic in nature because of the production of more secondary metabolites (Xuan et al., 2004). Some earlier studies have also reported the phytotoxic effect of aqueous extracts of leaves of weeds such as Mikania micrantha Kunth (Ismail and Kumar, 1996), Cyperus rotundus L. (Quayyum et al., 2000), Parthenium hysterophorus L. (Batish et al., 2002a), Ageratum conyzoides L. (Batish et al., 2002b), Terminalia arjuna (Roxb.) Wight \& Arn. (Gulzar and Siddiqui, 2013).

Figure 1A: Effect of leaf extracts of Broussonetia papyrifera on \% germination of Triticum aestivum and Oryza sativa.

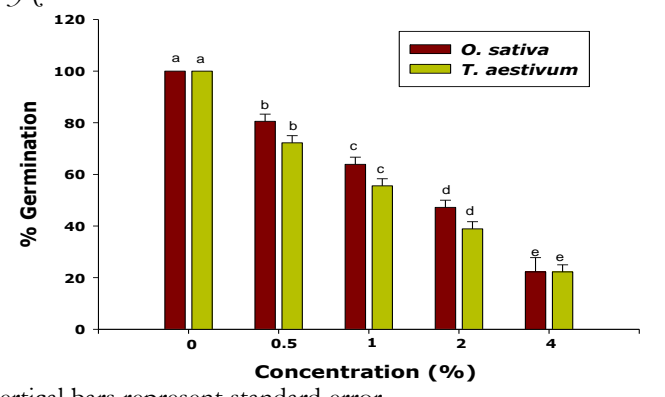

Vertical bars represent standard error.

Different alphabets represent significant difference among different concentration at $p \leq 0.05$ applying post hoc Tukey's test

Among the test crops, the reduction in the root and coleoptile length was more in $O$. sativa compared to T. aestivum. The root and coleoptile length of both the test plants were significantly $(p \leq 0.05)$ inhibited when treated with $0.5,1,2$ and $4 \%$ aqueous extracts prepared from leaves of $B$. papyrifera (Table 1). Our results are in agreement with Hussain and Reigosa (2011) who found the inhibitory effect of allelochemicals (phenolic compounds) on the root and shoot length of Dactylis glomerata L., Lolium perenne L. and Rumex acetosella L. The coleoptile length of $T$. aestivum and $O$. sativa was reduced by $45 \%$ and $61 \%$, respectively at highest concentration (4\%) compared to their respective controls. Nearly $55 \%$ and $62 \%$ reduction in root length of $T$. aestivum and $O$. sativa, respectively was measured at highest concentration compared to their respective controls. These results are in agreement with the results of Stachon and Zimdahl (1980) who reported that extracts of allelopathic plants have more inhibitory effect on root growth than hypocotyl growth.

Table 1: Effect of leaf extracts of Broussonetia papyrifera on root length, coleloptile length and seedling dry weight of Triticum aestivum and Oryza sativa.

\begin{tabular}{|c|c|c|c|c|c|c|}
\hline \multirow{2}{*}{$\begin{array}{c}\text { Concentration } \\
(\%)\end{array}$} & \multicolumn{2}{|c|}{ Root length (cm) } & \multicolumn{2}{|c|}{ Coleoptile length $(\mathrm{cm})$} & \multicolumn{2}{|c|}{ Seedling dry weight (mg) } \\
\hline & O. sativa & T. aestivum & O. sativa & T. aestivum & O. sativa & T. aestivum \\
\hline 0 & $8.12 \pm 0.04 \mathrm{a}(0)$ & $14.2 \pm 0.05 a(0)$ & $10.68 \pm 0.04 \mathrm{a}(0)$ & $7.74 \pm 0.11 \mathrm{a}(0)$ & $18.96 \pm 0.04 \mathrm{a}(0)$ & $35.4 \pm 0.14 \mathrm{a}(0)$ \\
\hline 0.5 & $6.42 \pm 0.04 \mathrm{~b}(15.58)$ & $12.42 \pm 0.06 \mathrm{~b}(12.53)$ & $8.64 \pm 0.07 \mathrm{~b}(19.1)$ & $5.8 \pm 0.10 \mathrm{~b}(25.06)$ & $15.34 \pm 0.05 b(19.09)$ & $31.32 \pm 0.06 \mathrm{~b}(11.52)$ \\
\hline 1 & $5.2 \pm 0.07 \mathrm{c}(35.96)$ & $10.44 \pm 0.05 \mathrm{c}(26.48)$ & $6.26 \pm 0.05 c(41.38)$ & $5.21 \pm 0.08 \mathrm{c}(32.68)$ & $13.44 \pm 0.07 \mathrm{c}(29.11)$ & $27.36 \pm 0.23 c(22.72)$ \\
\hline 2 & $3.94 \pm 0.08 \mathrm{~d}(51.48)$ & $8.66 \pm 0.08 \mathrm{~d}(39.01)$ & $5.12 \pm 0.06 \mathrm{~d}(52.06)$ & $4.94 \pm 0.07 \mathrm{c}(36.17)$ & $11.24 \pm 0.05 \mathrm{~d}(40.72)$ & $23.98 \pm 0.09 \mathrm{~d}(32.25)$ \\
\hline 4 & $3.12 \pm 0.04 \mathrm{e}(61.58)$ & $6.36 \pm 0.04 \mathrm{e}(55.21)$ & $4.16 \pm 0.05 \mathrm{e}(61.05)$ & $4.22 \pm 0.07 \mathrm{~d}(45.47)$ & $7.36 \pm 0.04 \mathrm{e}(61.18)$ & $21.38 \pm 0.13 \mathrm{e}(39.6)$ \\
\hline
\end{tabular}

Data presented as mean \pm standard error;

Different alphabets within a column represent significant difference among treatments at $p \leq 0.05$ applying post hoc Tukey's test;

Values within parenthesis represent percent decrease over control 
There was a significant reduction in seedling dry weight of both the test crops. The chlorophyll content of both the test crops was reduced (21 to $65 \%$ in T. aestivum and 30 to $55 \%$ in O. sativa) with increase in concentration of leaf extracts compared to their respective control (Fig. 1B). Earlier studies have also reported that allelochemicals including phenolics reduces the chlorophyll content and affect photosynthesis (Batish et al., 2007). The phenolics were also detected in the extracts and their amount increases with increasing extract concentration (Fig. 1C). The presence of significant amount of phenolics in the aqueous extracts of $B$. papyrifera suggested that the observed inhibition could be due to the presence of phenolic content (Mizutani, 1999; Xuan et al., 2005) (Fig.1C).

Figure 1B: Effect of leaf extracts of Broussonetia papyrifera on total chlorophyll content of coleoptiles of Triticum aestivum and Oryza sativa.

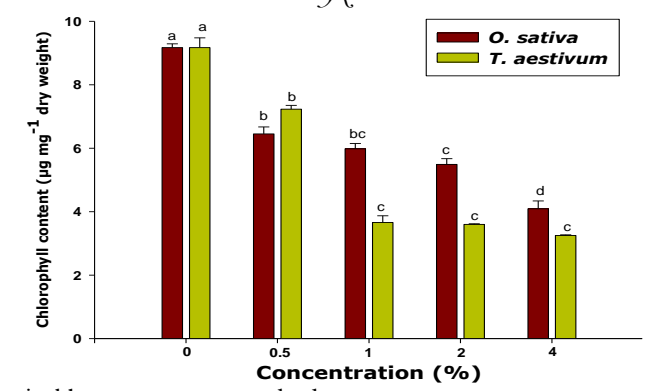

Vertical bars represent standard error

Different alphabets represent significant difference among different concentration at $p \leq 0.05$ applying post hoc Tukey's test

Figure 1C: Total phenolic content in the leaf extracts of Broussonetia papyrifera.

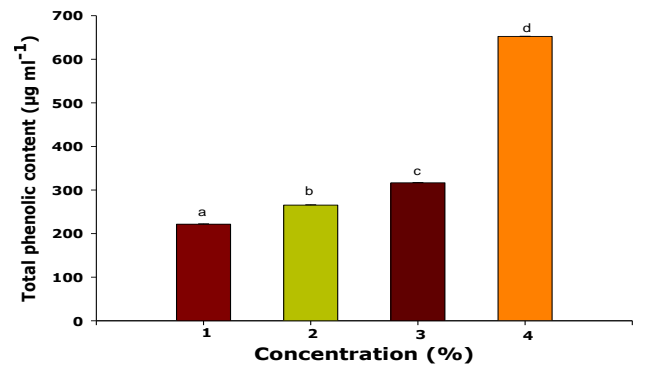

Vertical bars represent standard error

Different alphabets within a curve represent significant

difference among different concentration at $p \leq 0.05$ applying post hoc Tukey's test

\section{Conclusions}

The study concludes that leaves of B. papyrifera contain water soluble phenolics that inhibit germination, seedling growth and development. These phytotoxins probably come in contact with the growing seedlings of crop plants and cause injurious effects to them.

\section{Acknowledgement}

Anjana Negi is thankful to UGC, New Delhi for financial assistance in the form of fellowship.

\section{References}

1. Rice, E. L. "Allelopathy." Academic press, Orlando, FL, USA, 1984.

2. Kohli, R. K., D. R. Batish, and H. P. Singh. "Allelopathy and its implications in agroecosystems." Journal of Crop Production 1.1 (1997): 169-202.

3. Kohli, R. K., and D. Rani. "Parthenium bysterophorus-a review."Research Bulletin of the Panjab University, Science 44.1/4 (1994): 105-119.

4. Mann, J. "Secondary Metabolism." 2nd Edition. Clarendon Press, Oxford, 1987.

5. Malik, R. N., and S. Z. Husain. "Broussonetia papyrifera (L.) L'hér. Ex Vent.: an environmental constraint on the himalayan foothills vegetation." Pakistan Journal of Botany 39.4 (2007): 1045-1053.

6. Morghan E. C., and W. A. Overholt. "Wildland Weeds: Paper Muberry, Broussonetia papyrifera. ENY-702. Entomology and Nematology." Florida Cooperative Extension Service. University of Florida IFAS, 2004.

7. Hiscox, J. D., and G. F. Israelstam. "A method for the extraction of chlorophyll from leaf tissue without maceration." Canadian Journal of Botany 57.12 (1979): 1332-1334.

8. Arnon, D. I. "Copper enzymes in isolated chloroplasts. Polyphenoloxidase in Beta vulgaris." Plant Physiology 24.1 (1949): 1-15.

9. Rani, D. and R. K. Kohli. "Fresh matter is not an appropriate relation unit for chlorophyll content: Experience from experiments on effects of herbicide and allelopathic substance." Photosynthetica 25.4 (1991): 655-658.

10. Swain, T., and W. E. Hillis. "The phenolic constituents of Prunus domestica. I.-The quantitative analysis of phenolic constituents." Journal of the Science of Food and Agriculture 10.1 (1959): 63-68.

11. Xuan, T. D., T. Shinkichi, N. H. Hong, T. D. Khanh, and C. 111 Min "Assessment of phytotoxic action of Ageratum conyzoides L. (billy goat weed) on weeds." Crop Protection 23.10 (2004): 915-922.

12. Ismail, B. S., and A. Kumar. "Effects of aqueous extracts and residues decomposition of Mikania micrantha HBK on selected crops." Allelopatby Journal 3.2 (1996): 195-206. 
13. Quayyum, H. A., A. U. Mallik, D. M. Leach and C. Gottardo. "Growth inhibitory effects of nutgrass (Cyperus rotundus) on rice (Oryza sativa) seedlings." Journal of Chemical Ecology 26.9 (2000): 2221-2231.

14. Batish, D. R., H. P. Singh, J. K. Pandher, V. Arora, and R. K. Kohli. "Phytotoxic effect of Parthenium residues on the growth of radish and chickpea and selected soil properties." Weed Biology and Management 2.2 (2002): 73-78.

15. Batish, D. R., P. Tung, H. P. Singh, and R. K Kohli. "Phytotoxicity of sunflower residues against some summer season crops." Journal of Agronomy and Crop Science 188.1 (2002): 19-24.

16. Gulzar, A., and M. B. Siddiqui. "Evaluation for allelopathic impact of Terminalia arjuna (Roxb.) wight and arn bark against Cassia sophera." African Journal of Agricultural Research 8.39 (2013): 4937-4940.

17. Hussain, M. I., and M. J. Reigosa. "Allelochemical stress inhibits growth, leaf water relations, PSII photochemistry, nonphotochemical fluorescence quenching, and heat energy dissipation in three C3 perennial species." Journal of Experimental Botany 62.13 (2011): 4533-4545.

18. Stachon, W. J., and R. L. Zimdahl. "Allelopathic activity of Canada thistle (Cirsium arvense) in Colorado." Weed Science 28.1 (1980): 83-86.

19. Batish, D. R., H. P. Singh, R. K. Kohli, S. Kaur, D. B. Saxena, and S. Yadav. "Assessment of phytotoxicity of parthenin."Zeitschrift für Naturforschung C 62.5-6 (2007): 367-372.

20. Mizutani, J. "Selected allelochemicals." Critical Reviews in Plant Sciences 18.5 (1999): 653-671.

21. Xuan, T. D., S. Tawata, T. D. Khanh, and I. M. Chung "Decomposition of allelopathic plants in soil." Journal of Agronomy and Crop Science 191.3 (2005): 162-171.

\section{Cite this article as:}

Anjana Negi, Daizy R. Batish, Harminder Pal Singh and R. K. Kohli. Allelopathic Effect of Leaves of Invasive tree Broussonetia papyrifera against some crop plants. Annals of Plant Sciences 5.1 (2016): 1261-1264. 